\title{
Fertility maintenance in male oncological patients: current state and future perspectives
}

\author{
Kubikova $\mathrm{E}^{1}$, Klein $\mathrm{M}^{2}$, Svitok $\mathrm{P}^{3}$, Stefanic $\mathrm{J}^{2}$, Benus $\mathrm{R}^{4}$, Polak $\mathrm{S}^{2}$, Varga $\mathrm{I}^{2}$ \\ Institute of Anatomy, Faculty of Medicine, Comenius University in Bratislava, Slovakia. \\ eliska.kubikova@fmed.uniba.sk
}

\begin{abstract}
Growing cancer incidence in reproductive age goes hand in hand with a rising survival rate of patients who underwent anticancer therapy. This trend points to the necessity of discussion regarding the fertility maintenance. The patient's future with respect to his reproductive ability has to be addressed properly to achieve a complex approach to cancer management. The germinal epithelium of the testes is highly susceptible to deleterious effects of chemotherapy. After the administration of gonadotoxic chemotherapeutic agents, a patient can develop oligospermia, or even azoospermia. Similarly, radiation exposure can damage spermatogenesis, while higher doses lead to azoospermia. This review brings an overview of the methods of assisted reproduction, which are currently in use for fertility maintenance in oncological patients, but also in those with non-malignant indications. Also, novel, yet still experimental, methods are discussed, which represent promising technologies applicable to prepubertal oncological patients. We also discuss historical milestones in the development of assisted reproduction, summarize the options of semen analysis, and we present a practical guide through the process of sperm cryopreservation and subsequent in vivo or in vitro fertilisation. We deem that fertility maintenance should be an integral part of the health care in oncological patients in reproductive age (Tab. 1, Ref. 85). Text in PDF www.elis.sk.

KEY WORDS: assisted reproduction technique, sperm cryopreservation, testicular tissue cryopreservation, spermatogenesis, sperm quality in oncological patients.
\end{abstract}

\section{Historical introduction}

Assisted reproduction is a medical field focused on different physiological aspects of male and female gametes and embryos in in vitro conditions, while its principal aim is infertility treatment. Although the major goal is female conception and carrying a pregnancy to term, assisted reproduction currently encompasses also the issues of cryopreservation (freezing) of the reproductive cells, and also genetic testing before the embryo is placed into the uterus. Clinical embryology is one of the most recent biomedical fields, whose upswing dates back to 1978, when the first "test-tube" baby was born. A significant contribution to the development of in vitro fertilisation method is attributed to Patrick Steptoe, Sir Robert Edwards and Jean Marian Purdy (Brinsden and Brinsden 2009, Gosden, 2018, Steptoe, 2015). In former Czechoslovakia, the first baby, as the result of assisted reproduction, was born in Brno in 1982. This procedure was carried out by the team of specialists,

${ }^{1}$ Institute of Anatomy, Faculty of Medicine, Comenius University in Bratislava, Slovakia, ${ }^{2}$ Institute of Histology and Embryology, Faculty of Medicine, Comenius University in Bratislava, Slovakia, ${ }^{3} \mathrm{GYN}-\mathrm{FIV}$, Centre for Gynaecology, Urology and Assisted Reproduction, Bratislava, Slovakia, and ${ }^{4}$ Department of Anthropology, Faculty of Natural Sciences, Comenius University in Bratislava, Slovakia

Address for correspondence: I. Varga, RND, PhD, Institute of Histology and Embryology, Faculty of Medicine, Comenius University in Bratislava, Sasinkova 4, SK-811 08 Bratislava, Slovakia. namely a gynaecologist Professor Ladislav Pilka, in collaboration with embryologists from Masaryk University in Brno, Professors Milan Dvořák, Pavel Trávník and Jan Tesařík. As a method, they used a direct transfer of the in vitro fertilized egg into the uterine tube, at that time a unique approach, known today as gamete intrafallopian transfer (Tesařík et al, 1983, Pilka et al, 1984).

Cryopreservation of sperm, oocytes and embryos (colloquially known as "freezing"), plays a central role in assisted reproduction today (Rodriguez-Wallberg, 2015). It can be shortly characterized as a process, which preserves the reproductive cells, embryos, and also tissues from reproductive glands by the means of rapid freezing in liquid nitrogen at its boiling point (minus $196^{\circ} \mathrm{C}$ ), enabling future usage. The first case of a successful fertilization using cryopreserved and subsequently thawed human sperm was published in 1953 (Bunge a Sherman, 1953). More than 60 years after this ground-breaking event, we can state that the achievements of "cryobiology" have resulted in several million children born from cryopreserved sperm, so far. Good example of an enormous benefit of sperm cryopreservation is the maintenance of fertility in patients with oncological diseases before the onset of chemotherapy and/ or radiotherapy (Abram McBride and Lipshultz, 2018, Qu et al, 2019). Not only that, this method has a much broader spectrum of indications, e.g. sperm banking in donation programmes, sperm preservation for future use (for instance as a prevention of such situation when a man is unable to ejaculate because of his distress just before the artificial insemination, or in case of age or disease- 
related worsening of the spermiogram). Nowadays, several other alternative circumstances, which motivate patients to undergo sperm cryopreservation are common, e.g. it can be viewed as "a prevention" for men undergoing vasectomy who are afraid of the unchangeable nature of their decision, or as a preventive measure before traveling to areas with the danger of Zika virus infection (Feinberg, 2017). However, new technologies and scientific advancements often bring plenty of unanswered ethical and legal questions, for example the issue of cryopreserved sperm utilization after donor's death.

\section{Sperm, ejaculate examination and spermiogram}

Sperm is a haploid cell, highly specialized in a shape, which arises from the process called spermatogenesis, occurring within the convoluted seminiferous tubules of the testes. Spermatogenesis comprises mitotic division of diploid spermatogonia, their subsequent meiotic division, but also the morphological transformation of immotile round spermatids into small motile sperm (Fayomi and Orwig 2018, Nakata 2019, Sharma et al, 2019a). This process takes around 74 days, after which the morphologically mature, yet still immotile sperm cells spend 12 more days travelling within the intratesticular ducts, efferent ductules, but mostly within the epididymal duct. We distinguish two cell populations, which are absolutely essential in the process of spermatogenesis - supporting cells of Sertoli, providing mechanical support, nutrition and immunological protection (formation of the blood-testis barrier) for developing sperm, and interstitial endocrine cells of Leydig, responsible for the production of testosterone (Balko et al, 2017, Staub and Johnson, 2018).

Sperm is about 60 micrometres long, consisting of three parts - head, neck and tail (flagellum). The head includes a condensed nucleus with the paternal genetic information and a membranebound cap-like organelle - the acrosome. The acrosome is considered a large secretory vesicle / lysosome that contains several enzymes including glycohydrolases, proteases, esterases, acid phosphatases, and aryl sulfatases. The release of these hydrolytic enzymes degrade the zona pellucida allowing the spermatozoa to penetrate it and join with the oocyte. In human spermatozoa, the acrosome occupies 40 to $70 \%$ of the head (Tello-Mora et al, 2018). The sperm neck contains two centrioles. One centriole corresponds to the basal body of the system of specifically arranged microtubules (the axonemal complex of the flagellum), while the second one is used during the zygote cleavage after the fertilization, since the oocyte doesn't contain its own centriole. The initial portion of the flagellum, termed the middle piece, is the area of spirally arranged mitochondria forming the mitochondrial sheath, the site of energy production required for the sperm movement. After the fertilization, these mitochondria are actively destroyed by the oocytes lysosomes (Balko et al, 2017). Sperm is a peculiar type of cell, as it doesn't contain any stored nutritive substances whatsoever, depending totally on diffusion from its surroundings. The sole energy source is glucose, and its proper function also requires calcium ions. Although, the lifespan of sperm cells is limited to several days, their ability to move is exceptional
(1-4 mm/min, what equals approximately $15-70 \mu \mathrm{m} / \mathrm{s}$ ). Another remarkable feature of the sperm is that their cytoplasm contains proteins essential for the induction of the mitotic division of the fertilized egg, known as sperm-borne oocyte-activating factors (Yeste et al, 2017).

Ejaculate (semen) is an organic fluid, which is formed by mixing of secretory products from various parts of the male genital system, namely the Sertoli cell-derived testicular fluid, and the secretions from the prostate, seminal and bulbourethral gland. Even though the sperm are fundamental components of the ejaculate, they minimally contribute to its total volume. This fact is noticeable after vasectomy, which results in the decrease of the total semen volume by only $10 \%$. Besides, this figure includes also the testicular fluid produced by supporting Sertoli cells, not only the volume of sperm alone, which is even lower (Weiske, 1994).

Examination of the ejaculate and semen analysis (spermiogram) is the most important procedure before sperm cryopreservation takes place (it should be the first examination on the list of infertile couples, which helps to determine the contribution of the "male factor"). Before the semen analysis, 2-5 days of sexual abstinence is recommended. Summarized in a simplified way, the basic laboratory examination of the ejaculate comprises:

- Evaluation of the volume, $\mathrm{pH}$, and liquefaction of the ejaculate - factors reflecting mainly the functional state of the accessory sex glands (the prostate and seminal gland),

- Microscopic evaluation of the sperm count (number of sperm per millilitre), their motility (particularly their progressive movement), and morphology (proportion of the sperm with normal shape and size) - indicators of the functional state of the testes and individual components of the reproductive tract,

- The ejaculate is also microscopically examined for the presence of white and red blood cells (leucocytospermia a hematospermia), epithelial cells and immature forms of sperm (Alipour et al, 2017, Balko et al, 2017, World Health Organisation, 2010).

The evaluation of the sperm concentration is performed using either a counting chamber (e.g. Makler's, or Bürker's counting chamber) or an automatic analyser (Alipour et al, 2017, Ber-Hava et al, 2000). These tools enable to count the number of sperm in one millilitre, or even in the whole ejaculate. It is important to note that the interpretation of acquired results should be done exclusively by an experienced expert in the field. The reason is that the spermiogram results can considerably vary in a relatively short time span, so no definitive conclusions should be made from a one-time analysis. The best demonstration of this phenomenon are the results of Elzanaty (2008), who concluded that the ejaculate volume and sperm concentration can be strongly influenced by acute stress reaction, which is experienced by some men during the compulsory masturbation in the centres of assisted reproduction.

The number of sperm or their concentration represent one of the most important and most commonly monitored parameters. The first, almost 100 years old, reference of the assessment of average sperm concentration is attributed to Macomber and Sanders (1929). According to their observations, the average number of sperm in one millilitre of the ejaculate is 100 million. In the 
Tab. 1. Recommended reference values of the spermiogram (normozoospermia), according the World Health Organization (WHO, 2010).

\begin{tabular}{lcc}
\hline & 5 percentile & 50 percentile \\
\hline Ejaculate volume & $1.5 \mathrm{ml}$ & $3.7 \mathrm{ml}$ \\
Sperm cell concentration & $15 \mathrm{million} / \mathrm{ml}$ & 73 million $/ \mathrm{ml}$ \\
Total sperm cell count & 39 million/ ejaculate & 255 million/ejaculate \\
Overall motility & $40 \%$ & $61 \%$ \\
Progressive motility & $32 \%$ & $55 \%$ \\
Normal morphology & $4 \%$ & $15 \%$ \\
\hline
\end{tabular}

1950s, several authors, e.g. Danish andrologist Richard Hammen or American physician John MacLeod established the lowest limit of sperm number necessary for successful fertilization to 60 million per millilitre. In 1945, MacLeod examined 100 otherwise healthy medical students, and concluded that as many as $65 \%$ of them have more than 100 million sperm per millilitre (MacLeod a Heim, 1945). However, in 1979, MacLeod re-evaluated his previous findings and determined that the cut-off value necessary for natural fertilization to occur should be lowered to 20 million per millilitre (MacLeod a Wang, 1979). The latest World Health Organization recommendation from 2010 (WHO, 2010) (Tab. 1) set the current lowest limit of normal sperm number to 15 million per millilitre. On the contrary, many experts hold the opinion that anything below 40 million, if you like 20 million per millilitre significantly reduces the chance of natural conception, so the WHO recommendations should be revised (e.g. Skakkebaek, 2010). Many authors postulated that the reduction of sperm number is something we must get ready for, considering that over the last 20 years the sperm count in the Western countries have been diminishing by $2.1-2.5 \%$ per year (Auger et al, 1995, Shine et al, 2008). We have been witnessing a similar drop also in the volume of the ejaculate, from $3.4 \mathrm{ml}$ to $2.75 \mathrm{ml}$ (Carlsen et al, 1992). This reduction is known as oligospermia - the medical term for a reduced number of otherwise normal sperm (from the perspective of their motility and morphology). Cryptozoospermia describes a medical condition in which the sperm occurrence is the ejaculate is so sparse that in order to locate at least some, the semen has to be centrifuged ( $\mathrm{Ku}$ et al, 2018). A complete absence of sperm in the ejaculate is termed azoospermia. According to our research, genetically conditioned disorders such as Klinefelter syndrome or AZF microdeletion of the Y chromosome, account for more than $8 \%$ of all azoospermia cases (Behulová et al, 2011). Contrary to popular belief, abnormally high sperm count, known as polyzoospermia (greater than 250 million spermatozoa / $\mathrm{ml}$ ) has also detrimental effect on fertility - most of the spermatozoa of polyzoospermic men do not undergo the acrosome reaction in vitro (Töpfer-Petersen et al, 1987).

The issue of firm definition of a "normal" sperm count is relatively challenging. Is it the arithmetic mean, or the statistical mode corresponding to the most commonly occurring value? Is it the sperm concentration, which leads to conception, or merely a consensus of professional organizations? One example for all, which demonstrates the challenging and complex nature of this issue, is the research by Professor Shanna H. Swan. She examined the sperm count of American men, who had already fathered an offspring. The results were remarkable. While the sperm count of men from New York read the value 102.9 million per millilitre, that of Californians showed only 80.8 million, while Missourians and Iowans had the lowest count -58.7 million and 48 million per millilitre, respectively (Swan, 2006). These geographical differences had been one of the reasons why the WHO recommended, that each individual laboratory should elaborate its own standards grounded in the research on volunteers. This is, however, considerably problematic.

Based on the results of semen analysis, a set of additional specialized tests can be indicated, although many of them are not routinely performed in all assisted reproduction centres across the board (e.g., Abu-Heija et al, 1997, Agarwal et al, 2017, Evenson 2013; Evenson 2016, Losano et al, 2018, Tello-Mora et al, 2018, Sharma et al, 2019b, World Health Organisation 2010):

- The evaluation of sperm vitality (in seemingly dead, immotile sperm) using the hypoosmotic test,

- The evidence of IgA and IgG autoantibodies on the surface of sperm (mixed antiglobulin reaction), indicating a damage of blood-testis barrier. This immunological factor dampens the chance for a successful natural conception,

- Fragmentation of the sperm DNA (sperm chromatin structure assay),

- Diagnosis of aneuploidies by fluorescence in situ hybridization,

- Microscopic evaluation of stained semen smear,

- Sperm-cervical mucus interaction test,

- Assessment of sperm oxidative stress, including assessment of sperm mitochondrial function,

- Acrosome reaction test.

\section{The effect of cancer treatment on testes and spermatogenesis}

Today's estimate of male cancer incidence indicates that one in two men will develop an oncological disease at some point in his life, from which $4 \%$ will be under 35 years of age. A traditional approach to anticancer treatment is focused on the elimination of the cancer tissue itself, however an increasing efficiency and safety goes hand in hand with the rise of long-term survival rate of young adults who underwent this therapy. Five-year survival rate in patients under 15 years old undergoing anticancer therapy is 75 $\%$. In patients between 15-44 years of age, this rate is estimated at $66 \%$. Increasing occurrence of these encouraging data clearly indicates that fertility maintenance in oncological patients should belong to the list of issues of major importance before, during and after the cancer treatment. Fertility can be jeopardized by the pathophysiological specifics of the oncological disease, but also by the treatment employed. While some treatment regimens cause "only" reversible infertility, in 50-95\% of malignant oncological diseases, the infertility is permanent. This is the main reason why the discussion concerning the fertility maintenance should be of paramount importance in male oncological patients (Osterberg et al, 2014). It is underlined by the evidence that anticancer treatment is potentially harmful not only to testes directly, but also to 
hypothalamo-hypophyseal axis, which controls the function of the male gonads.

The germinal epithelium of the testes is highly susceptible to harmful effects of chemotherapy, regardless of the patient's age at the onset of the treatment. Thus after the administration of gonadotoxic substances, a patient can develop oligospermia, or even azoospermia. The production of testosterone by interstitial endocrine cells of Leydig usually remains unaffected, so secondary sex characteristics develop normally (Wallace et al, 1991). Nevertheless, when the gonadotoxic effect of chemotherapy is evaluated from the perspective of cumulative dose, interstitial endocrine cells of Leydig are no longer able to tolerate this detrimental burden, so their dysfunction is presumably inevitable (Gerl et al, 2001). Some data indicate that the proportion of patients with mild dysfunction of Leydig cells and biochemical, as well as clinical hypogonadism after chemotherapy, can be higher than previously thought (Romerius et al, 2009). Low levels of testosterone result in a number of clinically relevant conditions, including osteoporosis, metabolic syndrome, cardiovascular diseases and erectile dysfunction, so the monitoring of testosterone levels and subsequent hormone replacement therapy (if necessary) is of great importance (Stanworth and Jones, 2008).

Radiation doses of 0.1-1.2 Gy can disrupt spermatogenesis, while doses higher than 4 Gy cause a permanent azoospermia. It was observed that supporting Sertoli cells are more resistant than spermatogonia. Dysfunction of interstitial endocrine cells of Leydig is not detectable, until the radiation exposure reaches $20 \mathrm{~Gy}$ in prepubertal patients and $30 \mathrm{~Gy}$ in men after sexual maturity (Shalet et al, 1989). Within the paediatric and adolescent age group, the testicular damage occurs after a direct radiation exposure of the testes, e.g. during therapy of leukaemia (Castillo et al, 1990). Patients with leukemic infiltration of the testes usually undergo the radiation therapy with doses of $24 \mathrm{~Gy}$, resulting in a permanent azoospermia (Grundy et al, 1997).

Total body irradiation is the main etiological factor of azoospermia in patients after hematopoietic stem cell transplantation. Patients who underwent total body irradiation at the dose of at least $7.5 \mathrm{~Gy}$ are at the greatest risk of infertility (Savani, 2006). The results of a large retrospective cohort study - European Group for Blood and Marrow Transplantation showed that as much as $81 \%$ of patients after total body irradiation manifested with azoospermia, and as little as $1 \%$ of patients had normal sperm count after the therapy (Rovo et al, 2013). Long-term observation in patients with longer than ten-year survival rate, who were under 25 years old at the time of hematopoietic stem cell transplantation and without evident graft-verus-host disease, showed that these patients had a real chance that their spermatogenesis remained preserved (however, only to extent below the official WHO cut-off values), despite receiving total body irradiation in regular dosage (Rovo et al, 2006). Earlier study focused on the influence of graft-versushost disease on fertility in patients after hematopoietic stem cell transplantation with diagnosed aplastic anaemia, who didn't undergo total body irradiation, only chemotherapy, concluded that the patient's chance to father his own child was around $50 \%$. In patients with a diagnosed graft-versus-host disease, the rate was considerably lower, to be specific $29 \%$. In patients without the graft-versus-host disease, this rate was $62 \%$ (Deeg, 1998). Therefore, it is not completely clear, whether the sterilising effect of this chronic disease is caused by the graft reaction against the host, or it can be considered simply as the result of its chronic course and its consequential repercussions (Tichelli a Rovo, 2013).

\section{Sperm quality in oncological patients and the influence of sperm cryopreservation on this variable}

Many papers have been published so far, confirming the chemotherapy or radiotherapy-induced testicular damage. However, the issue of potentially negative influence of the testicular neoplasm itself (before any treatment) on the spermiogram parameters is still controversial. The majority of current studies are on the same page that, according to the WHO 2010 criteria, the spermiogram is worsened in approximately half of the patients with testicular cancer (e.g. MacKenna et al, 2017, Auger et al, 2016). Luisa Caponecchia, an Italian embryologist, together with her team, performed the spermiogram in 128 men with diagnosed testicular cancer. The sperm concentration in the study group (men with cancer), was significantly lower compared to the results of the control group (healthy volunteers) - the median was 18 million per millilitre in the study group against 46.5 million per millilitre in the control group. Similarly, the sperm motility was also lowered, however, the sperm morphology was not negatively influenced by the cancer. The authors also disproved any deterioration in the spermiogenesis related to the pT1, pT2, or pT3 stages of the cancer (Caponecchia et al, 2016). Similar conclusions were made also by the recent French study, according to which the patients with testicular cancer have approximately one fourth of the sperm number, in comparison to healthy volunteers (average $36.1 \pm 48.5$ million sperm per millilitre). Approximately half of the patients with testicular cancer had normal spermiogram results (Auger et al, 2016). However, the same study pointed out that apart from testicular cancer, other types of oncological diseases (e.g. leukaemia, lymphoma, brain tumour, sarcoma), but also autoimmune systemic conditions (e.g. sclerosis multiplex and Behcet's disease) can also worsen the ejaculate quality. It is necessary to emphasize that many other factors can influence the spermiogram parameters, including age (Eskanazi et al, 2003, Sloter et al, 2006), duration of the sexual abstinence (Sunanda et al, 2014), lifestyle, environmental factors, or even a season (sperm concentration in summer accounts for about $70 \%$ of the value during winter) and geographical location (Jorgensen et al, 2001). Still, the exact mechanism, by which the oncological disease negatively influences the spermatogenesis is not known. Supposed etiopathogenesis is often linked to congenital abnormalities of the reproductive cells, systemic effect of a tumour, or negative influence of cytokines and hormones produced by the cancer tissue (Trottmann et al, 2007).

Global statistics shows that from among men who underwent a treatment due to an oncological disease, approximately $8 \%$ actually use their cryopreserved sperm to artificially inseminate their significant others (Ferrari et al, 2016). Even though the sperm of 
oncological patients showed a significantly reduced motility and vitality after thawing, in case of a successful fertilization, no abnormalities were observed during the cleavage of the zygote, and in addition, the rate of embryo implantation into the uterine mucosa was also comparable with the control group (Depalo et al, 2016). The research conducted by the team of specialists from Masaryk University in Brno, Czech Republic (Záková et al, 2014) was in accordance with the abovementioned results, as it showed that patients with testicular cancer whose sperm cells had been cryopreserved before a treatment will have a good chance to father a child someday. According to the archive of this department, between 1995 and 2012; the cohort of 523 patients (mean age 28.5 \pm 6.6 years) with testicular cancer had undergone sperm cryopreservation before a treatment, from which 34 individuals later decided to use these sperm in assisted reproduction. This resulted in 16 pregnancies from 46 cycles of artificial fertilization (pregnancy rate was $34.8 \%$ ). The average elapsed time from the sperm collection to the patient's decision to actually use these samples in the cycles of artificial fertilization was $22.2 \pm 14.7$ months.

\section{Laboratory methods of sperm cryopreservation}

Cryopreservation is a technique, which enables to preserve tissue components including cells using cryogenic temperatures. Human sperm cryopreservation is an integral and inseparable part of the technology of assisted reproduction, and represents an effective method of male fertility maintenance, e.g. during a treatment of oncological diseases (Stern and Agresta, 2019). This technique of cryogenic preservation is especially important in patients treated with chemotherapy and radiotherapy, both of which can lead to testicular dysfunction or ejaculation impairment (di Santo et al, 2012). In fact, it seems that sperm cryopreservation is the only proven method, which can give patient a chance to have children in future. The cancer treatment can lead to that kind of damage, which results in subfertility or even sterility due to the removal of gonads or because of an irreversible deterioration of the reproductive cells caused by adjuvant therapy. The treatment-associated risks depend on various individual factors such as patient's age at the time of treatment, dosage and type of therapy applied (Jensen et al, 2011). As already mentioned, the benefit of sperm cryopreservation is not the exclusive matter of oncological patients, as there are many non-malignant diseases like diabetes mellitus or autoimmune disorders which can also lead to testicular damage. So, in these cases, sperm cryopreservation is also recommended (Anger et al, 2003).

Sperm cryopreservation comprises multiple conventional cryogenic preservation techniques. Slow freezing technique, as suggested by Behrman and Sawada (1966) is based on progressive freezing of the semen, either manually or automatically using a programmable freezer. Principle of the manual technique is the addition of cryoprotective agent, and subsequent lowering of the temperature. The optimal initial speed of the sample cooling from the laboratory temperature to $5^{\circ} \mathrm{C}$ was determined to be $0.5-1$ ${ }^{\circ} \mathrm{C} / \mathrm{min}$. After that, the sample is cooled from $5^{\circ} \mathrm{C}$ to $-80{ }^{\circ} \mathrm{C}$ at the speed of $1-10{ }^{\circ} \mathrm{C} / \mathrm{min}$, and is subsequently immersed into liquid nitrogen which freezes it to $-196{ }^{\circ} \mathrm{C}$ (Mahadevan a Troun- son, 1984). However, the reproducibility of the manual technique methodology was showed to be a bit problematic, so despite the reports of successful sperm preservation, it was recommended to use a programmable freezer.

Freezers use a straw-holding plate, in which the straws are frozen by liquid nitrogen stored in a container under the plate. After liquid nitrogen is poured into the container, the machine gradually decreases the temperature from $20^{\circ} \mathrm{C}$ to $-80{ }^{\circ} \mathrm{C}$ at the speed of $1.5^{\circ} \mathrm{C} / \mathrm{min}$, the process is then accelerated to $6^{\circ} \mathrm{C} / \mathrm{min}$. After the procedure is finished, the straws are stored in liquid nitrogen at $-196{ }^{\circ} \mathrm{C}$ (Holt, 2000).

Rapid freezing technique, as put forward by Sherman (1990), requires a direct contact of sperm-containing straws with liquid nitrogen vapours during $8-10$ minutes. Next step is immersion in liquid nitrogen at $-196^{\circ} \mathrm{C}$. Within the liquid nitrogen vapours, a thermal gradient is formed, depending on the distance from the liquid underneath and its volume. Firstly, the samples are mixed with equal amount of cryoprotective agent, the mixture is put into straws, which are then situated about $15-20 \mathrm{~cm}$ above the liquid nitrogen surface. During the freezing process, the best method is to position the straws horizontally to minimize the temperature difference between both ends of the straw. Another technique of sperm cryopreservation is vitrification. In this process, semen is mixed with cryoprotectants, sealed off in a plastic straw and then tossed directly into liquid nitrogen. This method is not routinely used in laboratories, so far.

Despite its undisputed usefulness, cryopreservation can result in deleterious changes in the structure and function of the sperm. While the cryobiology of other cells is well known, scientific literature lacks a consensus regarding the harmful effects on human sperm. Nevertheless, sperm cryopreservation is a crucial technique in the fertility management, what is well proved by its successful application in assisted reproduction (Di Santo et al, 2012).

\section{A practical guide through the process of sperm cryopreserva- tion and subsequent fertilization}

Considering the potentially detrimental effect of cancer treatment on quality and quantity of sperm cells, it is of paramount importance that the semen is cryopreserved before the onset of therapeutic intervention. According to the study by American team of researchers, sperm cryopreservation was undergone by $30 \%$ of patients in reproductive age with diagnosed oncological disease. Oncological patients, who are more willing to undergo this procedure, are those of higher socioeconomic status, but also men who do not identify themselves with any religious denomination (Klosky et al, 2009). A physician-oncologist is in charge of the first important step, which is to properly inform a patient about the options of sperm storage for future use. In the United States of America, as many as $91 \%$ of oncologists agreed with sperm cryopreservation in oncological patients before treatment, however $48 \%$ of them admitted, they hold a proper discussion concerning this method with only less than one quarter of patients. The reasons are assorted, usually it is a shortage of time for a dialogue, but also (disproportionate) assumption of excessive financial demands for a patient (Schover et al, 2002). 
485-493

Semen collection is not recommended during or shortly after the oncological treatment, so it is all-important to advise a patient to visit a specialized department engaged in assisted reproduction sufficiently ahead of time. A patient should bring his medical chart with properly recorded oncological diagnosis, along with the results from serological testing for HIV, hepatitis B, syphilis and other sexually transmitted diseases. For semen storage out of a quarantine container, the examination for sexually transmitted infections is absolutely essential.

The number of semen collections required for the storage of sufficient amount of material depends on various factors such as ejaculate quality, health status of a patient, type of cancer, time elapsed from the onset of an oncological treatment, and last but not least the method of assisted reproduction, for which the sample will be used (Nangia et al, 2013). Most of the departments recommend to store at least three ejaculate samples with a minimum of two day gap between collections, if the patient's health status is satisfactory and the postponement of treatment is acceptable. For semen collection, a patient can use a special isolated room within the premises of assisted reproduction centre. Some departments even allow a significant one to be present during the collection, if it is a wish of the patient. If a centre of assisted reproduction is located nearby a patient's domicile, there is a possibility to collect the sample at home into fit-for-purpose container. Methodology of the following semen usage must be in accordance with the type of procedure employed during prospective assisted reproduction. We distinguish three general approaches to oocyte fertilization: intrauterine insemination (IUI), classic in vitro fertilization (IVF) and intracytoplasmic sperm injection (ICSI).

Intrauterine insemination is the easiest method of assisted reproduction, but its usage has certain limitations. There are several prerequisites, which ought to be fulfilled. Success rate of this method is dependent on the patency of the uterine tubes. At the commencement of IUI, sperm washing including the removal of any possible microbial contaminants or foreign substances must be performed. Later on, only motile sperm cells are selected, which are subsequently injected, using a special catheter, directly into the uterine cavity during ovulation. Thus, from the perspective of cryopreservation, the cardinal requirement is that the preserved sample contains properly motile sperm in a high concentration, as these two factors are of utmost importance when it comes to the success of this method (Nangia et al, 2013). The main advantages of IUI are that, neither oocyte retrieval, nor general anaesthesia are required. In case of inadequate quality of thawed sperm cells, an attending gynaecologist, with specialty in reproductive medicine normally recommends a more efficient method of infertility treatment, generally in vitro fertilization.

In vitro method is one of the basic approaches of external fertilization. It consists of the following individual steps:

- Stimulation of the growth of ovarian follicles (via the administration of hormone therapy drugs),

- Transvaginal oocyte retrieval - aspiration of the oocyte from the ovary using a special puncture needle through the vaginal wall ("oocyte puncture"), in short general anaesthesia under transvaginal ultrasound guidance,
- Semen collection and processing (sperm washing - separation of sperm from the seminal fluid, removal of potential bacteria, blood cells, as well as dead and immotile sperm), or thawing of cryopreserved sperm,

- Co-incubation of the sperm and oocyte in a culture medium,

- Embryo cultivation during different stages of early embryogenesis (zygote, cleavage stages (morula), blastocyst) after successful fertilization,

- Placement of the embryo into the uterine cavity, also known as embryo transfer. In the presence of multiple embryos, some of them can by cryopreserved and used later on (Řezábek, 2014).

However, classic in vitro fertilization also requires, similarly as intrauterine insemination, a higher sperm concentration with an adequate motility, so it is necessary to cryopreserve samples of high quality. In case of suboptimal spermiogram results, sperm cryopreservation should be repeated.

Intracytoplasmic sperm injection into the oocyte is another technique used in assisted reproduction. This method is considered as a partial solution of male infertility, as it is feasible also in patients with low sperm count and inadequate sperm motility. This method even allows sperm harvesting directly from the tissue of the testis or epididymis. ICSI is based on injection of one particular sperm using a special needle directly into the oocyte cytoplasm. This whole process is performed using a specialized inverted microscope with two "arms" attached to electronically-assisted device (micromanipulator), which enables high precision of movement. One arm bears a holding micropipette, stabilizing the oocyte in place, while the other contains an injection micropipette, which is used for the sperm transfer into to the oocyte cytoplasm. Firstly, the sperm which is used in this procedure is immobilized by detaching the sperm tail with a micropipette. This is an inevitable step, as the sperm movement could damage the inner structure of the oocyte. Moreover, this procedure triggers a discharge of special proteins from the sperm known as sperm-borne oocyte-activating factors, which facilitate the fertilization process (Neri et al, 2014; Amdani et al, 2015). The advantage of ICSI is that the number of sperm cells needed equals the number of oocytes obtained during the puncture. It follows that, ICSI represents a suitable method even for those couples, in which the female body produces antibodies against the partner's sperm. On top of that, this method is feasible even with a minimum number of cryopreserved sperm.

ICSI also ensures a precise selection of mature sperm, which are used during fertilization. It is also an advantage, because mature sperm were demonstrated to be significantly less susceptible to chromosome abnormalities (Žáková et al, 2012). An embryologist has several options at disposal to select "the best", i.e. mature sperm. Firstly, he can focus on the sperm morphology, which can be examined using differential interference contrast microscopy (Nomarski interference contrast/Nomarski microscopy). At high magnification, this approach is suitable for a study of lowcontrast details of the sperm. This method is called "intracytoplasmic morphologically selected sperm injection" (IMSI). However, the recent randomized controlled trial has not demonstrated any statistically significant increase in the live birth rate using 
IMSI, when compared to "classic" ICSI (Teixeira et al, 2013). Second alternative is the usage of hyaluronic gel, which has the ability to mimic the oocyte surface along with the cells of $\mathrm{co}^{-}$ rona radiata (supporting follicular cells). Arguably, only mature sperm possess hyaluronic-binding receptors, so the utilization of such sperm rises the chance of successful fertilization (Žáková et al, 2010). This method is termed "preselected ICSI" (PICSI). Another option is to use presumably one of the newest methods magnetic-activated cell sorting (MACS). Sperm cells with a high rate of DNA fragmentation are tagged using superparamagnetic nanoparticles, which are subsequently trapped inside a separation column. Intact sperm cells without DNA fragmentation are free to pass through this special column, so they can be used in ICSI.

\section{Future perspectives: testicular tissue cryopreservation in pre- pubertal patients}

Sperm cryopreservation is a relatively simple and effective method for fertility maintenance in oncological patients before the start of gonadotoxic cancer treatment. However, the main challenge are the cases of patients in prepubertal age, as the absence of spermatogenesis makes it impossible for them to benefit from this procedure. Experiments using animal models have indicated that cryopreserved spermatogonia can be successfully used in regeneration of damaged spermatogenesis. However, the application of such experiment to human medicine is dubious. To the best of authors' knowledge, only one department (Wake Forest Institute for Regenerative Medicine, USA), is currently active in testicular tissue cryopreservation of prepubertal oncological patients obtained from biopic samples (Sadri-Ardekani et al, 2016). Up to now, researchers from this department were able to cryopreserve samples from 14 boys, however they themselves describe this procedure as "experimental". Nevertheless, these experts assume that in near future, this preserved tissue will be usable (if necessary) for the purpose of fertility restoration in these child patients. However, until that time many individual issues must be resolved, e.g. elimination of potential cancer cells "contamination" of the cryopreserved tissue prior to auto-transplantation, development of methodology for reimplantation of harvested testicular tissue after treatment, perhaps even development of laboratory modalities for in vitro development of sperm from spermatogonia. Similar methodologies and recommendations already exist for cryopreservation of tissue from ovarian cortex in women before the initiation of oncological treatment. Even though more than 35 children have already been born after the auto-transplantation of the ovarian tissue (Stoop et al, 2014), the exact fate of the transplanted tissue still remains unknown, moreover it is also only partially understood for how long this transplanted tissue will be able to constitute an adequate ovarian reserve.

\section{Conclusion}

Thanks to advances in chemotherapy, radiotherapy and surgical treatment, we have been witnessing a significant increase in five-year survival rate of the patients with testicular cancer. Indeed, these exceptional results should go hand in hand with an increased demand for sperm cryopreservation (Caponecchia et al, 2016). Gonadotoxicity of chemotherapy is a variable influenced by multitude of factors like age, cumulative dosing, or past testicular surgeries. In any case, some chemotherapeutic agents definitely cause an irreversible damage of the reproductive glands. Similarly, radiotherapy performed in specific locations can also cause a dose-dependent direct damage of testes or hypothalamo-hypophyseal axis. Ergo, it is necessary to keep in mind that the loss of fertility during oncological treatment is an up-to-date issue, which represents also a source of serious chronic psychosocial deprivation. According to several studies, 50-70\% of oncological patients would like to have their own children in the future (Trottmann et al, 2007). Whereas a lot of patients are still uninformed or at least inadequately informed about these possibilities of fertility maintenance (this is also the case of women in reproductive age with diagnosed oncological disease), many internationally-renowned professional medical organizations, e.g. American Society of Clinical Oncologists, American Society for Reproductive Medicine, or National Comprehensive Cancer Network, have already published their recommendations. Fertility maintenance should be "personalized" for each patient according to many variables such as patient's age, type of oncological disease, character of prescribed therapy, or time remaining until the initiation of given treatment.

Despite these problems, we think that fertility maintenance should be an integral part of heath care provided for oncological patients. International guidelines recommend that physicians should discuss, as early as possible, with all patients of reproductive age their risk of infertility from the disease and/or treatment and their interest in having children after cancer, and help with informed fertility preservation decisions. This complex management has a potential to comfort the patient, who is given a chance to father his own child, and this hope alone has a great power to help overcome all the difficulties associated with the cancer treatment (Lambertini et al, 2016, Martinez et al, 2017).

\section{References}

1. Amdani SN, Yeste M, Jones C, Coward K. Sperm factors and oocyte activation: current controversies and considerations. Biol Reprod 2015; 93 (2): 50.

2. Anger JT, Gilbert BR, Goldstein M. Cryopreservation of sperm: indications, methods and results. J Urol 2003, 170 (4 Pt 1): 1079-1084.

3. Auger J, Kunstmann JM, Czyglik F, Jouannet P. Decline in semen quality among fertile men in Paris during the past 20 years. N Engl J Med 1995; 332 (5): 281-285.

4. Auger J, Sermondade N, Eustache F. Semen quality of 4480 young cancer and systemic disease patients: baseline data and clinical considerations. Basic Clin Androl 2016; 26: 3.

5. Balko J, Tonar Z, Varga I. (Eds). Memorix histology. Praha. Triton; 2018. $584 \mathrm{pp}$.

6. Behrman SJ, Sawada Y. Heterologous and homologous inseminations with human semen frozen and stored in a liquid-nitrogen refrigerator. Fertil Steril 1966; 17 (4): 457-466.

7. Behulova R, Varga I, Strhakova L, Bozikova A, Gabrikova D, Boronova I, Repiska V. Incidence of microdeletions in the AZF region of the Y chromosome in Slovak patients with azoospermia. Biomed Pap Med Fac Univ Palacky Olomouc Czech Repub 2011; 155 (1): 33-38. 
8. Bunge RG, Sherman JK. Fertilizing capacity of frozen human spermatozoa. Nature 1953; 172: 767-768.

9. Caponecchia L, Cimino G, Sacchetto R, Fiori C, Sebastianelli A, Salacone P, Marcucci I, Tomassini S, Rago R. Do malignant diseases affect semen quality? Sperm parameters of men with cancers. Andrologia 2016; 48 (3): 333-340.

10. Carlsen E, Giwercman A, Keiding N, Skakkebaek NE. Evidence for decreasing quality of semen during past 50 years. BMJ 1992; 305 (6854): 609-613.

11. Castillo LA, Craft AW, Kernahan J, Evans RG, Aynsley-Green A. Gonadal function after 12-Gy testicular irradiation in childhood acute lymphoblastic leukaemia. Med Ped Oncol 1990; 18: 185-189.

12. Deeg HJ, Leisenring W, Storb R, Nims J, Flowers ME, Witherspoon RP, Sanders J, Sullivan KM. Long-term outcome after marrow transplantation for severe aplastic anemia. Blood 1998; 91 (10): 3637-3645.

13. Depalo R, Falagario D, Masciandaro P, Nardelli C, Vacca MP, Capuano P, Specchia G, Battaglia M. Fertility preservation in males with cancer: 16-year monocentric experience of sperm banking and post-thaw reproductive outcomes. Ther Adv Med Oncol 2016; 8 (6): 412-420.

14. Di Santo M, Tarozzi N, Nadalini M, Borini A. Human sperm cryopreservation: Update on techniques, effect on dna integrity, and implications for ART. Adv Urol 2012; 2012: 854837.

15. Elzanaty S. Time-to-ejaculation and the quality of semen produced by masturbation at a clinic. Urology 2008; 71 (5): 883-888.

16. Eskenazi B, Wyrobek AJ, Sloter E, Kidd SA, Moore L, Young S, Moore D. The association of age and semen quality in healthy men. Hum Reprod 2003; 18 (2): 447-454.

17. Feinberg EC. Advances in cryopreservation: we are not frozen in time. Fertil Steril 2017; 108 (5): 763.

18. Ferrari S, Paffoni A, Filippi F, Busnelli A, Vegetti W, Somigliana E. Sperm cryopreservation and reproductive outcome in male cancer patients: a systematic review. Reprod Biomed Online 2016; 33 (1): 29-38.

19. Gerl A, Muhlbayer D, Hansmann G, Mraz W, Hiddemann W. The impact of chemotherapy on Leydig cell function in long term survivors of germ cell tumors. Cancer 2001; 91: 1297-1303.

20. Grundy RG, Leiper AD, Stanhope R, Chessells JM. Survival and endocrine outcome after testicular relapse in acute lymphoblastic leukaemia. Arch Dis Child 1997; 76: 190-196.

21. Holt WV. Basic aspects of frozen storage of semen. Anim Reprod Sci 2000; 62 (1-3): 3-22.

22. Jensen JR, Morbeck DE, Coddington CC 3rd. Fertility preservation. Mayo Clin Proc 2011; 86 (1): 45-49.

23. Jørgensen N, Andersen AG, Eustache F, Irvine DS, Suominen J, Petersen JH, Andersen AN, Auger J, Cawood EH, Horte A, Jensen TK, Jouannet P, Keiding N, Vierula M, Toppari J, Skakkebaek NE. Regional differences in semen quality in Europe. Hum Reprod 2001; 16 (5): 1012-1019.

24. Klosky JL, Randolph ME, Navid F, Gamble HL, Spunt SL, Metzger ML, Daw N, Morris EB, Hudson MM. Sperm cryopreservation practices among adolescent cancer patients at risk for infertility. Pediatr Hematol Oncol 2009; 26 (4): 252-260.

25. MacKenna A, Crosby J, Huidobro C, Correa E, Duque G. Semen quality before cryopreservation and after thawing in 543 patients with testicular cancer. JBRA Assist Reprod 2017; 21 (1): 31-34.

26. MacLeod J, Heim LM. Characteristics and variations in semen specimens in 100 normal young men. J Urol 1945; 54: 474-482.

27. MacLeod J, Wang Y. Male fertility potential in terms of semen quality: a review of the past, a study of the present. Fertil Steril 1979; 31: 103-116.
28. Macomber D, Sanders MB. The spermatozoa count. N Engl J Med 1929; 200: 981-984

29. Mahadevan M, Trounson AO. Effect of cooling, freezing and thawing rates and storage conditions on preservation of human spermatozoa. Andrologia 1984; 16 (1): 52-60.

30. Maršík L, Bielik P. Základy asistovanej reprodukcie. Učebnica reprodukčnej medicíny. Zvolen: Technická univerzita, 2014, $170 \mathrm{~s}$.

31. Nangia AK, Krieg SA, Kim SS. Clinical guidelines for sperm cryopreservation in cancer patients. Fertil Steril 2013; 100 (5): 1203-1209.

32. Neri QV, Lee B, Rosenwaks Z, Machaca K, Palermo GD. Understanding fertilization through intracytoplasmic sperm injection (ICSI). Cell Calcium 2014; 55 (1): 24-37.

33. Osterberg ECH, Ramasamy R, Masson P, Brannigan RE. Current Practices in Fertility Preservation in Male Cancer Patients. Urology Annals 2014; 6 (1): 13-17.

34. Pilka L, Dvorák M, Tesarík J, Trávnik P, Soska J, Cupr Z. Personal experience with in vitro fertilization and embryo transfer (Unsere erfahrungen mit der in vitro fertilisation und dem embryotransfer). Zentralbl Gynakol 1984; 106 (13): 928-931.

35. Řezábek K. Asistovaná reprodukce. Druhé aktualizované a doplněné vydání. Praha: Maxdorf, 2014. 138 s.

36. Romerius P, Stahl O, Moell C, Relander T, Cavallin-Ståhl E, Wiebe T, Giwercman YL, Giwercman A. Hypogonadism risk in men treated for childhood cancer. J Clin Endocrinol Metab 2009; 94: 4180-4186.

37. Rovó A, Aljurf M, Chiodi S, Spinelli S, Salooja N, Sucak G, Hunter A, Kim TS, Socié G, van Lint MT, Passweg JR, Arat M, Badoglio M, Tichelli A, Late Effects Working Party of the EBMT. Ongoing graftversus-host disease is a risk factor for azoospermia after allogeneic hematopoietic stem cell transplantation: a survey of the Late Effects Working Party of the European Group for Blood and Marrow Transplantation. Haematologica 2013; 98 (3): 339-345.

38. Rovó A, Tichelli A, Passweg JR, Heim D, Meyer-Monard S, Holzgreve W, Gratwohl A, De Geyter C. Spermatogenesis in long-term survivors after allogeneic hematopoietic stem cell transplantationis associated with age, time interval since transplantation, and apparently absence of chronic GvHD. Blood 2006; 108 (3): 1100-1105.

39. Sadri-Ardekani H, McLean TW, Kogan S, Sirintrapun J, Crowell K, Yousif MQ, Hodges SJ, Petty J, Pranikoff T, Sieren L, Zeller K, Atala A. Experimental testicular tissue banking to generate spermatogenesis in the future: A multidisciplinary team approach. Methods 2016; 99: 120-127.

40. Savani BN, Kozanas E, Shenoy A, Barrett AJ. Recovery of spermatogenesis after total-body irradiation. Blood 2006; 108 (13): 4292-4293.

41. Schover LR, Brey K, Lichtin A, Lipshultz LI, Jeha S. Oncologists' attitudes and practices regarding banking sperm before cancer treatment. J Clin Oncol 2002; 20 (7): 1890-1897.

42. Shalet SM, Tsatsoulis A, Whitehead E, Read G. Vulnerability of the human Leydig cell to radiation damage is dependent upon age. J Endocrinol 1989; 120: 161-165.

43. Sherman J. Cryopreservation of human semen. In. Keel B, Webster BW. (Eds). Handbook of the Laboratory Diagnosis and Treatment of Infertility. Boca Raton: CRC Press, 1990

44. Shine R, Peek J, Birdsall M. Declining sperm quality in New Zealand over 20 years. N Z Med J 2008; 121 (1287): 50-56.

45. Skakkebaek NE. Normal reference ranges for semen quality and their relations to fecundity. Asian J Androl 2010; 12 (1): 95-98.

46. Sloter E, Schmid TE, Marchetti F, Eskenazi B, Nath J, Wyrobek AJ. Quantitative effects of male age on sperm motion. Hum Reprod 2006; 21 (11): 2868-2875. 
47. Stanworth RD, Jones TH. Testosterone for the aging male, current evidence and recommended practice. Clin Interv Aging 2008; 3: 25-44.

48. Stoop D, Cobo A, Silber S. Fertility preservation for age-related fertility decline. Lancet 2014; 384 (9950): 1311-1319.

49. Sunanda P, Panda B, Dash C, Padhy RN, Routray P. Effect of age and abstinence on semen quality: A retrospective study in a teaching hospital. Asian Pacific J Reprod 2014; 3 (2): 134-141.

50. Swan SH. Semen quality in fertile US men in relation to geographical area and pesticide exposure. Int J Androl 2006; 29 (1): 62-68.

51. Teixeira DM, Barbosa MA, Ferriani RA, Navarro PA, Raine-Fenning N, Nastri CO, Martins WP. Regular (ICSI) versus ultra-high magnification (IMSI) sperm selection for assisted reproduction. Cochrane Database Syst Rev 2013; (7): CD010167.

52. Tesařík J, Pilka L, Dvorák M, Trávník P. Oocyte recovery, in vitro insemination, and transfer into the oviduct after its microsurgical repair at a single laparotomy. Fertil Steril 1983; 39 (4): 472-475.

53. Tichelli A, Rovo A. Fertility issues following hematopoietic stem cell transplantation. Expert Rev Hematol 2013; 6 (4): 375-388.

54. Trottmann M, Becker AJ, Stadler T, Straub J, Soljanik I, Schlenker B, Stief CG. Semen quality in men with malignant diseases before and after therapy and the role of cryopreservation. Eur Urol 2007; 52 (2): 355-367.

55. Wallace WH, Shalet SM, Lendon M, Morris-Jones PH. Male fertility in long-term survivors of childhood acute lymphoblastic leukaemia. Int J Androl 1991; 14: 312-319.

56. Weiske WH. Minimal invasive vasektomie mittels fulgurationstechnik. erfahrungenbei 1000 patienten in 12 jahren. Urologe 1994; B34: 448-452.

57. World Health Organisation. WHO Laboratory Manual for the Examination and Processing of Human Semen, 5th Ed. Geneva: World Health Organization, 2010. $286 \mathrm{pp}$.

58. Yeste M, Jones C, Amdani SN, Coward K. Oocyte Activation and Fertilisation: Crucial Contributors from the Sperm and Oocyte. Results Probl Cell Differ 2017; 59: 213-239.

59. Žáková J, Lousová E, Crha I, et al, PICSI - selekce zralých spermií pro oplození lidských oocytů metodou ICSI. Prakt Gyn 2010; 14 (4): 180-182.

60. Záková J, Lousová E, Ventruba P, Crha I, Pochopová H, Vinklárková $\mathbf{J}$, Tesařová E, Nussir M. Sperm cryopreservation before testicular cancer treatment and its subsequent utilization for the treatment of infertility. ScientificWorldJournal 2014; 2014: 575978.

61. Žáková J, Ventruba P, Crha I, Lousová E, Sochorová K, Pohanka M, Huser M. Nové metody zvyšující úspěšnost asistované reprodukce. Ceska Gynekol 2012; 77 (2): 139-142.

62. Qu N, Itoh M, Sakabe K. Effects of Chemotherapy and Radiotherapy on Spermatogenesis: The Role of Testicular Immunology. Int J Mol Sci 2019; 20 (4). pii: E957.

63. Sharma S, Wistuba J, Pock T, Schlatt S, Neuhaus N. Spermatogonial stem cells: updates from specification to clinical relevance. Hum Reprod Update 2019a. doi: 10.1093/humupd/dmz006.

64. Nakata H. Morphology of mouse seminiferous tubules. Anat Sci Int 2019; 94 (1): 1-10.

65. Staub C, Johnson L. Review: Spermatogenesis in the bull. Animal 2018; 12 (s1): s27-s35.

66. Abram McBride J, Lipshultz LI. Male Fertility Preservation. Curr Urol Rep 2018; 19 (7): 49.

67. Fayomi AP, Orwig KE. Spermatogonial stem cells and spermatogenesis in mice, monkeys and men. Stem Cell Res 2018; 29: 207-214.
68. Tello-Mora P, Hernández-Cadena L, Pedraza J, López-Bayghen E, Quintanilla-Vega B. Acrosome reaction and chromatin integrity as additional parameters of semen analysis to predict fertilization and blastocyst rates. Reprod Biol Endocrinol 2018; 16 (1): 102.

69. Evenson DP. The Sperm Chromatin Structure Assay (SCSA (®)) and other sperm DNA fragmentation tests for evaluation of sperm nuclear DNA integrity as related to fertility. Anim Reprod Sci 2016; 169: 56-75.

70. Evenson DP. Sperm chromatin structure assay (SCSA $\left.{ }^{\circledR}\right)$. Methods Mol Biol 2013; 927: 147-164.

71. Abu-Heija AT1, Fleming R, Jamieson ME, Yates RW, Coutts JR. The predictive value of the sperm-cervical mucus interaction test on the outcome of in vitro fertilization and ovulation induction combined with intrauterine insemination. Aust N Z J Obstet Gynaecol 1997; 37 (2): 232-234.

72. Sharma R, Gupta S, Henkel R, Agarwal A. Critical evaluation of two models of flow cytometers for the assessment of sperm DNA fragmentation: an appeal for performance verification. Asian J Androl 2019b (in press). doi: 10.4103/aja.aja_109_18.

73. Losano JDA, Angrimani DSR, Ferreira Leite R, Simões da Silva BDC, Barnabe VH, Nichi M. Spermatic mitochondria: role in oxidative homeostasis, sperm function and possible tools for their assessment. Zygote 2018; 26 (4): 251-260.

74. Agarwal A, Qiu E, Sharma R. Laboratory assessment of oxidative stress in semen. Arab J Urol 2017; 16 (1): 77-86.

75. Steptoe A. Biology: Changing the world - a tribute to Patrick Steptoe, Robert Edwards and Jean Purdy. Hum Fertil (Camb) 2015; 18 (4): 232-233.

76. Brinsden PR, Brinsden PR. Thirty years of IVF: the legacy of Patrick Steptoe and Robert Edwards. Hum Fertil (Camb) 2009; 12 (3): 137-143.

77. Gosden R. Jean Marian Purdy remembered - the hidden life of an IVF pioneer. Hum Fertil (Camb) 2018; 21 (2): 86-89.

78. Bar-Hava I, Perri T, Ashkenazi J, Shelef M, Ben-Rafael Z, Orvieto R. The rationale for requesting a second consecutive sperm ejaculate for assisted reproductive technology. Gynecol Endocrinol 2000; 14 (6): 433-436.

79. Alipour H, Van Der Horst G, Christiansen OB, Dardmeh F, Jørgensen N, Nielsen HI, Hnida C. Improved sperm kinematics in semen samples collected after $2 \mathrm{~h}$ versus 4-7 days of ejaculation abstinence. Hum Reprod 2017; 32 (7): 1364-1372.

80. Ku FY, Wu CC, Hsiao YW, Kang YN. Association of sperm source with miscarriage and take-home baby after ICSI in cryptozoospermia: a metaanalysis of testicular and ejaculated sperm. Andrology 2018; 6 (6): 882-889.

81. Töpfer-Petersen E, Völcker C, Heissler E, Schill WB. Absence of acrosome reaction in polyzoospermia. Andrologia 1987; 19 Spec No: 225-228.

82. Rodriguez-Wallberg KA. Clinical aspects and perinatal outcomes after cryopreservation of embryos and gametes. Minerva Ginecol 2015; 67 (2): 207-215.

83. Stern C, Agresta F. Setting up a fertility preservation programme. Best Pract Res Clin Obstet Gynaecol 2019; 55: 67-78.

84. Martinez F, International Society for Fertility Preservation - ESHRE -ASRM Expert Working Group. Update on fertility preservation from the Barcelona International Society for Fertility Preservation-ESHRE-ASRM 2015 expert meeting: indications, results and future perspectives. Fertil Steril 2017; 108 (3): 407-415.e11.

85. Lambertini M, Del Mastro L, Pescio MC, Andersen CY, Azim HA Jr, Peccatori FA, Costa M, Revelli A, Salvagno F, Gennari A, Ubaldi FM, La Sala GB, De Stefano C, Wallace WH, Partridge AH, Anserini P. Cancer and fertility preservation: international recommendations from an expert meeting. BMC Med 2016; 14: 1 . 